\title{
Study of the Biological Activities of the Seeds of the Plant Ceratonia Siliqua L. Recovered in the Bejaia Region
}

\author{
Type of article: Conference abstract \\ Nabahat Benmansour 1, Hamida Cherif1, F. El Hanballi2, Mohamed Akssira2 \\ 1 Department of Biology, Faculty SNV, Blida, 09000, Algeria \\ 2Faculty of Science and Technology, Mohammedia, Morocco \\ Corresponding Author: nabahats@yahoo.fr
}

\begin{abstract}
:
Background: Ceratonia siliqua is a plant that belongs to the Fabaceae family. It is frequently used in our culinary and medical traditions to fight cholesterol, acute diarrhea and digestive disorders.

Methods: The hydrogen atom or electron donation abilities of the corresponding extracts and some pure compounds were measured from the bleaching of the purple-colored methanol solution of 2, 20-diphenylpicrylhydrazyl (DPPH), studying the anti-inflammatory effect by measuring the volume of the edema of the paw that has received carrageenan $1 \%$. Antimicrobial activity in vitro was screened by using disc diffusion and micro-dilution methods.

Results: The determination of the polyphenols of the methanolic extracts of the seeds reveals the richness of our extracts in polyphenols is $30 \mathrm{mg}$ of gallic acid / $\mathrm{g}$ of extract. The aqueous and methanolic extract flavonoid assay shows that they contain high levels of flavonoids with contents of 07 and $10 \mathrm{mg}$ equivalent of quercetin / $\mathrm{g}$ of extract respectively. The aqueous and methanolic extracts of Ceratonia siliqua seeds from the Bejaia region could bring the stable free radical 2.2 diphenyl-1-picrylhydrazyl (DPPH) to yellow-colored diphenylpicrylhydrazine with respective IC 50 values of $0.7 \mathrm{mg} / \mathrm{ml}$ and $0.2 \mathrm{mg} / \mathrm{ml}$. They exhibit lower antioxidant activity than ascorbic acid $(0.038 \mu \mathrm{g} / \mathrm{ml})$. Determination of antiinflammatory activity revealed that our aqueous and methanolic extracts of Ceratonia siliqua $L$ seeds are able to reduce edema up to $81.89 \%$. The methanoid extracts of Ceratonia siliqua $L$. seeds have a medium antibacterial action against bacteria: E. coli $(13 \mathrm{~mm})$, Staphylococcus aureus $(12 \mathrm{~mm})$ and Pseudomonas aeruginosa $(12 \mathrm{~mm})$. On the other hand, the aqueous extracts of the seeds of Ceratonia siliqua $L$ have a weak antibacterial action against the same bacteria with a diameter of inhibition of $9 \mathrm{~mm}$. However, the aqueous extracts of Ceratonia siliqua $L$ seeds are endowed with a very important inhibitory action against candida albicans and it is similar to that of the antibiotic, antifungal Econazole (1\%).

Conclusion: According to the results observed, the two extracts of the seeds and pods have a potential anti-free radical and antioxidant measured compared to the standard antioxidant used. The results of the antimicrobial activity carried out in vitro on the 3 bacterial strains indicate that the two methanolic extracts of this plant have low antibacterial activity.
\end{abstract}

Keywords: Fabaceae, Ceratonia Siliqua, Secondary Metabolites, Polyphenols, Antioxidant Activity, Antimicrobial Activity, Reducing Power. 


\section{Conflict of interest statement}

This article is a conference abstract presented at the International Congress on Health Sciences and Medical Technologies, Tlemcen Algeria 5-7 December 2019, ICHSMT'19.

\section{Authors' biography}

No Biography.

\section{References}

[1] Burits, M., Bucar, F. 2000. Antioxidant activity of Nigella sativa essential oil. Phytotherapy Research 14: 323-328.

[2] Cuendet, M., Hostettmann, K., Potterat, O. 1997. Iridoid glucosides with free radical scavenging properties from Fagraea blumei. Helvetica Chimica Acta 80: 1144-1152.

[3] NCCLS (National Committee for Clinical Laboratory Standards), 1997. Performance Standards for antimicrobial disk susceptibility test, VIth ed. Wayne PA: Approved Standard, M2-A6. 